\title{
Quality control of high-performance concrete in high-rise construction during operation
}

\author{
Artem Davidyuk ${ }^{1, *}$ and Igor Rumyantsev ${ }^{2}$ \\ ${ }^{1}$ Moscow State University of Civil Engineering, Yaroslavskoe shosse, 26, Moscow, 129337, Russia
}

\begin{abstract}
With onset of the XXI century, the demand for construction of high-rise buildings with the load-bearing framework made of highperformance cast-in-situ concrete has increased many-fold in the construction sector. Specific features of the high-performance concrete of bearing structures in the situation of real operation of high-rise buildings are continuously studied by scientists and specialists all over the world, and regulatory and methodological documents are being complemented and adjusted. High-performance concretes and structures made of them possess some specific features that should be taken into account in quality control. The methods of concrete inspection and concrete strength evaluation described in GOST 18105 "Concretes. Guidelines on Testing and Evaluation of Strength" and GOST 22690 "Concretes. Evaluation of Strength by Mechanic Non-Destructive Test Methods" were written when precast reinforced concrete was predominantly used in the construction sector and were limited to the functions of intra-factory quality control of reinforced concrete products. At present, instruments for non-destructive testing using indirect methods are usually calibrated with the help of local destructions, as a rule, a pull out or rib shear test. The said methods are in fact indirect since they indicate the force of destruction of the surface layer of a structure.
\end{abstract}

\section{Introduction}

With onset of the XXI century, the demand for construction of high-rise buildings with the load-bearing framework made of high-performance cast-in-situ concrete has increased many-fold in the construction sector. To take care of high internal forces in bearing structures from loads related to high number of stories in buildings, bearing cast-in-situ reinforced concrete structures are erected using high-performance concretes - concretes of compressive strength grade B60 and higher (B80, B90), made using Portland cement clinker bonding. The most large-scale and exemplary project where high-performance concrete was widely used is Moscow International Business Center "Moscow-City" (Moscow-City MIBC), which construction continues for 20 years approximately (active construction commenced in 1998 and completion is scheduled for 2020). Completion of the main buildings of the complex took place in $2004-2017$; therefore, the experience of quality control of utilized high-performance concrete is a little more than 10 years and less

\footnotetext{
*Corresponding author: 7707061@mail.ru
} 
than that in the situation of project operation. Specific features of the high-performance concrete of bearing structures in the situation of real operation of high-rise buildings are continuously studied by scientists and specialists all over the world, and regulatory and methodological documents are being complemented and adjusted. The distinctive aspect of high-performance concrete behavior related to their specific features, construction work quality and operation conditions manifests in the course of building operation. Additional requirements to high-performance concrete strength testing are described in GOST 31914 'High-Performance Heavy-Weight and Fine-Grain Concretes for In-Situ-Cast Structures. Quality Control and Evaluation Guidelines'; however, taking into account the peculiarities of strength evaluation during operation and practices of technical inspection of buildings built using high-performance concrete, attention should be paid to the method of highperformance concrete strength testing during operation.

\section{Materials and methods}

High-performance concretes and structures therefrom are characterized by some specific features compared to commonly used concretes (up to B60 strength grade), which must be taken into account in the course of quality control. High modulus of elasticity and brittleness make them sensitive to the accuracy of procedures and fitment during tests by direct methods of concrete strength evaluation (shear test), necessitating limitation of some allowances provided for standards, which are acceptable for testing common concretes, but fail to give objective information about the quality of high-performance concretes.

Increased heat rise and the temperature gradient related thereto in structural mass combined with shrinkage (inherent and due to dewatering) largely affect concrete thermal stress status, crack resistance and strength in different structural zones. The increased quantities of bars and structural reinforcement pattern make concrete placing more difficult and influence concrete compaction, so that in real life it is lower than that of reference samples; therefore, the actual strength of concrete in structures might be lower than the strength of reference samples, and the strength established in the surface structural zones might be lower than in in-depth zones [5]. There are known cases of 2-fold underestimation of high-performance concrete strength evaluated using NDT methods (shear test) by specialists of some Moscow construction laboratories who followed standard methodologies and used traditional equipment like "Oniks" or "POS".

Quality control of high-performance concrete in each structure during building operation, the concrete age being more than a year, deserves special attention. For measuring strength of reinforced concrete structures after a long period of operation, it is better to calibrate NDT instruments using samples taken from structural reference points preliminarily evaluated as having maximal, intermediate and minimal concrete strength figures. In case of strength evaluation of concrete and reinforced concrete structures in operation, calibration of NDT instruments should take into account concrete moisture content and age, and corrosive power of the environment [1].

The concrete strength control and evaluation methods described in GOST 18105, 22690 were established at the time when precast reinforced concrete was predominant, so they were largely reduced to the functions of intra-factory quality control of reinforced concrete structures [6]. Adaptation of methods and tools for non-destructive testing of concrete strength encountered certain difficulties upon transition to wide-scale cast-in-situ house building [4]. The situation is even more complicated as regards inspection of reinforced concrete structures in operation, in particular, in addressing such tasks as:

calibration of NDT instruments for concretes with a priory unknown physic-mechanical and structural characteristics;

assessment of the influence of test conditions on readings on NDT instruments; 
assessment of the influence of changes in the concrete structural characteristics in the course of its long-term operation on the results of non-destructive strength testing [1].

At present, instruments for non-destructive testing using indirect methods are usually calibrated with the help of local destructions, as a rule, a pull out or rib shear test. The said methods are in fact indirect since they indicate the force of destruction of the surface layer of a structure. Actually, the ultimate tensile strength of concrete is determined, but the relation between the compression strength and tensile strength is ambiguous [7].

The method of determining concrete strength based on samples taken from structures according to GOST 28570 is much more informative as, in addition to determining traditional physic-mechanical properties of concrete such as ultimate compression and tensile strength, density and elasticity modulus, it allows obtaining information about the type, fraction composition and grain separation of a coarse aggregate, pore structure, presence of low-modulus impurities and newgrowths related to specific effects of the operation environment [1]. Taking into account that non-destructive test methods are based on indirect correlation dependencies of concrete strength on such properties as density, hardness and ultrasound pulse velocity, it would be natural to assume that a change in the test conditions might result in a change of such dependencies. One of the most widely spread factors is concrete moisture content [8].

The high-performance concrete quality control system has been polished since 2005 in the course of erection of cast-in-situ structures during construction of the high-rise buildings in Moscow-City MIBC. A consequence of one of the specific features of highperformance concrete has been found: formation of shrinkage cracking due to increased temperature rise at the background of inherent shrinkage and shrinkage due to dewatering, which impose additional limitations on applicability of inspection methods and concrete strength evaluation such as a more difficult finding a crack-free area of necessary size for a particular method of measurement. High-performance concrete specificity also entails that the actual concrete strength might be lower than the strength of reference samples made in the course of erection and the strength determined by non-destructive methods in surface zones of structures might be lower than the strength in in-depth zones.

Thus, to achieve reliable results of high-performance concrete inspection and strength evaluation, such works have to be performed by a combination of destructive and nondestructive methods. The principle is that for each structure under inspection, the data of concrete strength testing by indirect non-destructive methods are collected and compared through development of calibration curves against the results of direct testing of cores taken from structures or reference samples formed at the incoming inspection of concrete quality provided that such data are kept, or by the shear test. The resultant calibration curves may be used to determine strength only if the correlation factor is not less than 0.7 and the determination error does not exceed $15 \%$ [5].

\section{Results and discussion}

Strength determination of heavy concretes of design grades B60 and higher or when the mean concrete compression strength is $\mathrm{Rm} \geq 70 \mathrm{MPa}$ in cast-in-situ structures must be carried out taking into account GOST 31914. According to GOST 31914, the applicability of established calibration curves is evaluated based on two indices: the correlation factor and the concrete strength determination error. It is allowed to use established calibration curves to determine concrete strength in structures when the correlation factor is not less than 0.7 and the concrete strength determination error does not exceed $15 \%$. The correlation factor and concrete strength determination error are determined according to sub-section 6.5 of GOST 18105. In determining concrete strength based on cores taken from structures, it is recommended to use cores having a diameter of not less than $70 \mathrm{~mm}$ 
and polished bearing surfaces, and scale factor $\alpha=1$ because use of cores of a smaller diameter and smaller scale factor significantly increases the error of the results obtained [3]. Hence, to achieve reliable results, the high-performance concrete inspection and strength determination should be carried out by a combination of destructive and non-destructive methods. The principle is that for each structure under inspection, the data of concrete strength testing by indirect non-destructive methods are collected and compared through development of calibration curves against the results of direct testing of cores taken from structures or reference samples formed at the incoming inspection of concrete quality provided that such data are kept, or by the shear test method. The resultant calibration curves may be used to determine strength only if the correlation factor is not less than 0.7 and the determination error does not exceed $15 \%$ [5].

Table 1. Optimal combinations of test methods providing correct calibration [5].

\begin{tabular}{|c|c|c|}
\hline \multirow{2}{*}{$\begin{array}{c}\text { Design Concrete } \\
\text { Grade }\end{array}$} & \multicolumn{2}{|c|}{ Test Methods } \\
\hline & Indirect & Direct \\
\hline B60 & $\begin{array}{l}- \text { shock pulse method using } \\
\text { sclerometers with impact energy of } \\
\text { not less than } 0.2 \mathrm{~J}\end{array}$ & $\begin{array}{l}\text { - tests of reference samples } \\
\text { - shear test } \\
\text { - tests of cores from structures }\end{array}$ \\
\hline B80-B90 & $\begin{array}{l}\text { - shock pulse method using } \\
\text { sclerometers with impact energy of } \\
\text { more than } 2.0 \mathrm{~J}\end{array}$ & - tests of cores from structures \\
\hline
\end{tabular}

\section{Conclusions}

1. High-performance concretes and structures therefrom are characterized by some specific features: high elasticity modulus and brittleness, increased temperature rise, shrinkage (inherent and due to dewatering), increased quantities of bars and structural reinforcement pattern.

2. The high-performance concrete inspection and strength determination should be carried out by a combination of destructive and non-destructive methods.

3. For measuring strength of reinforced concrete structures after a long period of operation, it is better to calibrate NDT instruments using samples taken from structural reference points preliminarily evaluated as having maximal, intermediate and minimal concrete strength figures.

\section{References}

1. G.V. Nesvetaev, A.V. Kolleganov, N.A. Kolleganov, Naukovedenie Internet Journal 9, 2 (2017)

2. Russian Standard GOST 22690-2015

3. Russian Standard GOST 31914-2012

4. M.G. Korevitskaya, Stroitelnaya engineria, 1 (2005)

5. S.S. Kaprielov, Stroitelnye materialy, 2 (2012)

6. I.S. Lifanov, Metrology, means and methods of quality control in construction (Stroiizdat, Moscow, 1979)

7. G.V. Nesvetaev, Concretes: manual for institutions of higher education. $2^{\text {nd }}$ edition, revised and corrected (Phoenix, Rostov-on-Don, 2013)

8. G.V. Nesvetaev, Bezopasnost truda v promyshlennosti 2, 62-66 (2008) 